\title{
Congenital Diaphragmatic Hernia: Atypical Early X-Ray Presentation
}

\author{
Wasey WA ${ }^{1}$, Srivastava SK $^{2}$ \\ ${ }^{1}$ Dr Waiz A Wasey, MBBS, ${ }^{2}$ Shashank Kumar Srivastava, MBBS student, Final part II. Both are affiliated to Shadan Institute \\ of Medical Sciences, Teaching Hospital and Research Centre, Himayath Sagar Road, Hyderabad, Telangana, India.
}

Correspondence Address: Dr Shashank Kumar Shrivastava, E-mail: dr.shashankksrivastava@gmail.com.

\begin{abstract}
Congenital Diaphragmatic Hernia $(\mathrm{CDH})$ is a congenital malformation of the diaphragm that allows herniation of the abdominal organs into the thoracic cavity. The most common type of $\mathrm{CDH}$ is Bochdalek Hernia. It is seen commonly on the left side than right, the right side being protected by the liver. $\mathrm{CDH}$ is a life threatening condition, most likely due to pulmonary hypoplasia. We report a left sided Bochdalek Hernia in a preterm female newborn delivered by Caesarian section.
\end{abstract}

Keywords: Congenital Diaphragmatic Hernia, Bochdalek Hernia, Pulmonary Hypoplasia

\section{Introduction}

The incidence of Congenital diaphragmatic hernia is 1 in 3000 [1], most of them are left sided [2] as the right side is protected by the liver. The most common type of $\mathrm{CDH}$ is the posterolateral Bochdalek hernia. The other two types are the anterior Morgagni and hiatus hernia.

Often diagnosed late, the condition leads to poor prognosis, mainly due to its association with lung hypoplasia, as the abdominal contents that pass into the thoracic cavity prevent the formation of the lung.

Thus the outcome of the patient depends on early diagnosis and intervention. [3] The purpose of this case, is to bring into light the importance of physical examination in the diagnosis of $\mathrm{CDH}$.

\section{Case Presentation}

A 33 week old premature female, delivered by LSCS in view of maternal PIH, was admitted to the NICU in view of her respiratory distress. The baby had cried immediately after birth and her APGAR scores on early neonatal resuscitative measures were 6 and 7 at 1 and 5 minutes respectively.

She was cyanotic in apperance and had respiratory distress. Oxygen therapy was initiated and the baby was admitted into the NICU for futher management.

Manuscript received: $29^{\text {th }}$ June 2014

Reviewed: $10^{\text {th }}$ July 2014

Author Corrected: $20^{\text {th }}$ July 2014

Accepted for Publication: $31^{\text {st }}$ July 2014
Her Initial chest x-ray taken, showed a picture of respiratory distress with opacification of lungs (Image 1)

In view that she had no obvious malformations, she was being treated for respiratory distress and her saturations were monitored.

Due to her inability to maintain O2 saturations, she was inbutated and given ventilatory respiratory support, later in the afternoon. Despite treatment efforts, she was still in respiratory distress.

A careful physical examination then done, revealed a bulging in the left thoracic cavity, a scaphoid and less full abdomen and chest retractions.

Auscultation of her chest showed decreased heart sounds, decreased breath sounds and faint bowel sounds in the left thoracic cavity. A repeat chest x-ray at this point (Image 2) showed bowel loops in the left thoracic cavity.

Arterial Bloog Gas Investigation revealed respiratory acidosis. The patient at this point was diagnosed as having left sided Bochdalek type congenital hernia with pulmonary hypoplasia. She was then posted for surgical decompression and repair of hernia.

A transverse abdominal approach was used to reduce the hernia. Following the repair she improved significantly, and was later moved to room in with her mother (Image 3) 


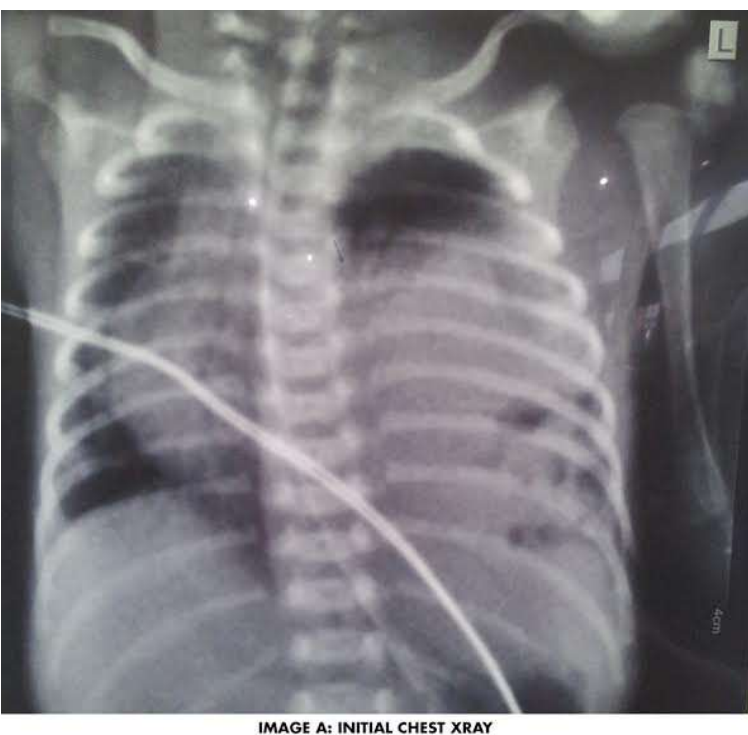

IMAGE A: INITIAL CHEST XRAY

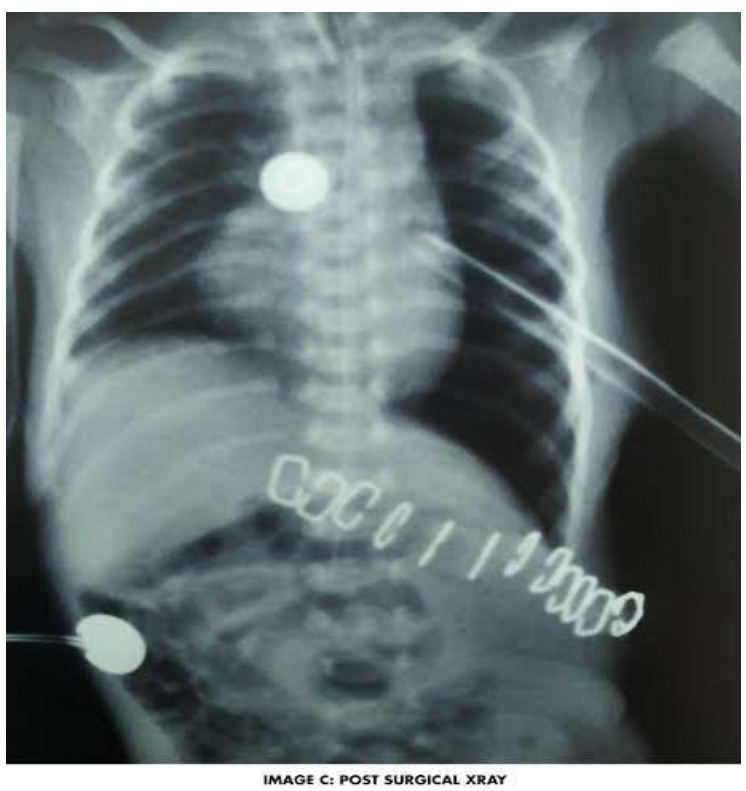

Investigations showed Repiratory Acidosis pH: 7.239, pCO2: $35.7 \mathrm{mmHg}$ (4.75 kPa), pO2: $109 \mathrm{mmHG}$ (14.50 $\mathrm{kPa})$

HCO3: $15.3 \mathrm{mmol} / \mathrm{L}, \mathrm{SO} \%$ : 97\%. Complete Blood Picture was suggested to thrombocytopenia $\mathrm{Hb}: 16.9$ gm/dl (169g/L), RBC Count: $4.78 \mathrm{mil} / \mathrm{cumm}$, WBC Count: 6,600 / cumm, Neutrophils: 52\%, Lymphocytes: $38 \%$, Platelets: 83,000 . CRP was positive and serum creatinine was $1.8 \mathrm{mg} / \mathrm{dl}$. Prothrombin time was 16 seconds \& INR: 1.24

\section{Abbreviations}

$\mathrm{CDH}$ : congenital diaphragmatic hernia, LSCS: low section caesarian section, NICU: neonatal intensive care unit, PIH: pregnancy induced hypertension, RDS: respiratory distress syndrome, $\mathrm{ABG}$ : arterial blood gases.

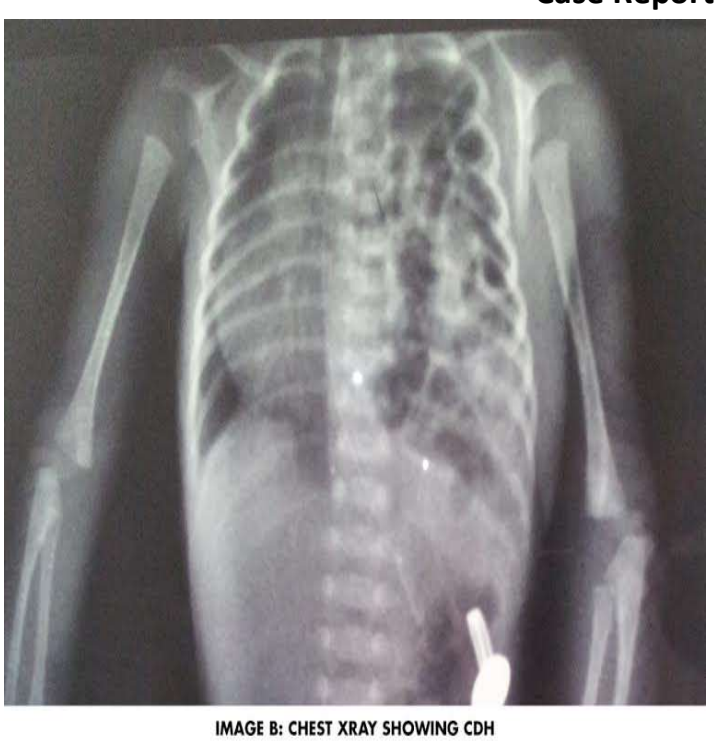

\section{Discussion}

$\mathrm{CDH}$ is a birth defect where an opening in the diaphgram muscle fails to close (prematurity) and the contents of the abdomen herniate into the chest cavity through the opened defect. The incidence is 1 in every 3000 live births. [1]

The herniation mostly occurs during the stage of lung development, which explains for the ipsilateral pulmonary hypoplasia. $2 \%$ of CDHs are believed to be familial, consistent with autosomal recessive, autosomal dominant and X-linked inheritence. $10 \%$ of CDHs occur as part of medical syndromes, [4] such as; Cornelia de Lange syndrome and Fryns syndrome [5]. 30\% of CHDs are due to chromosomal defects, such as; trisomies, Turner syndrome and Pallister-Killian syndrome. Some cases of CDHs due to vitamin A deficiency have also been reported. [6]. 3 types of CHD have been reported: Bochdalek hernia, Morgagni hernia and hiatus hernia. Most hernias are left sided (85\%) Bochdalek hernia [2] as in case of our patient. Bochdalek hernia is the postero lateral hernia and is the most common, accounting for $95 \%$ of the cases. The morgagni hernia is a rare anterior defect and accounts for only $2 \%$ of the cases.

The infants with $\mathrm{CDH}$ present with signs of respiratory distress (such as cyanosis, chest retractions and grunting) in the first few minutes of life. Examination of these patients show; a scaphoid abdomen, barrel shaped chest, and signs of respiratory distress. Chest auscultations show poor air entry, shift of cardiac sounds to the right and decreased breath sounds. [7] If a part of the syndrome; other defects such as craniofacial, extremity anomalies or spinal defects may also be seen. [8]. Some patients may survive till later to present with delayed 
manifestations such as mild respiratory distress following an airway infection or developed distress over time. [9]

The diagnostic workup includes ABG studies, serum lactate, chromosomal studies, electrolytes, glucose levels, chest xray, cardiac echo to rule out malformations [10], renal ultrasound, cranial sonography and cranial MRI. Antenatal diagnosis is relatively easier, using ultrasonography, indicators such as mediastinal shift, presence of bowels in thorax, small abdominal circumference and polyhydramnios can help detect $\mathrm{CDH}$ before birth. [11]. When the diagnosis is made in utero, amniocentesis must be performed to rule out chromosomal defects [12] as well as estimating the maturity of lung. [13]

If the diagnosis is made before birth, depending on the results from amniocentesis, the treatment may be done surgically or the pregnancy may be terminated in view of other chromosomal defects. [14] After birth the initial management includes stabilizing the patient with endotracheal intubation and mechanical ventilation, as a bridge to surgical correction. Care should be taken towards optimizing oxygenation to avoid barotraumic complications. [15] A orogastric tube is passed to decompress the bowels and prevent futher lung compression. Surfactant therapy has been tried in some cases, but the overall benefit has not been reported. [16] Extra corporeal membrane oxygenation (ECMO) is being used as an adjuvant therapy in the treatment of $\mathrm{CDH}$. Cannulation of right carotid artery and jugular vein, and they connection to a membrane gas exchange chamber helps in the oxygenation of the body and removal of carbon dioxide without the stress on the lungs [17].

Surgical repair done within 24-48 respond well, but should be considered after cardio respiratory stabilization. The surgery is aimed at reducing the herniated contents back into the abdomen. This is usually done with procedures requiring minimal invasion, such as laproscopy. If the defect is too large, prosthetic patches maybe used to close the defect [18].

$\mathrm{CDH}$ has a mortality rate of $40-60 \%$, especially if associated with a medical syndrome [19]. These outcomes also depend on genetics, size of hernia, duration, organs involved and lung development. With advances in surgery and post surgical care, the survival rate is now around $75 \%$.

\section{Conclusion}

Our case describes how in the absence of thorough physical examination, atypical x-rays can delay the diagnosis of congenital hernias. Taking into consideration, the prematurity and the haziness on chest $\mathrm{x}$-ray, the patient was provisionally diagnosed as having RDS. Early diagnosis of CDH is important for the overall prognosis of the patient. Thorough physical examination is neccesary in preterm infants who show significant respiratory distress despite initial Oxygen treatment. Once diagnosed, the patient should be sent for surgical correction as soon as possible to avoid pulmonary complications that may lead to increased morbidity and mortality.

\section{Funding: Nil}

\section{Conflict of interest: Nil}

\section{Permission from IRB: Yes}

\section{References}

1. Langham MR, Kays DW, Ledbetter DJ, Frentzen B, Sanford LL, Richards DS. Congenital diaphragmatic Hernia: Epidemiology and outcome. Clin Perinatol 1996 23: $671-88$.

2. Clark RH, Hardin WD Jr, Hirschl RB, Jaksic T, Lally KP, Langham MR Jr, Wilson JM. Current surgical management of congenital diaphragmatic hernia: a report from the Congenital Diaphragmatic Hernia Study Group. J Pediatr Surg. 1998;33:1004-1009

3. Lally KP, Lally PA, Lasky RE, Tibboel D, Jaksic T, Wilson JM, Frenckner B, Van Meurs KP, Bohn DJ, Davis $\mathrm{CF}$, Hirschl RB. Defect size determines survival in infants with congenital diaphragmatic hernia. Pediatrics. 2007;7:e651-e657

4. Zaiss I, Kehl S, Link K, Neff W, Schaible T, Sutterlin M, Siemer J. Associated Malformations in Congenital Diaphragmatic Hernia. Am J Perinatol. 2010

5. McPherson EW, Ketterer DM, Salsburey DJ. PallisterKillian and Fryns syndromes: nosology. Am J Med Genet. 1993;47:241-245

6. Clugston RD, Zhang W, Alvarez S, De Lera AR, Greer JJ. Understanding Abnormal Retinoid Signaling as a Causative Mechanism in Congenital Diaphragmatic Hernia. Am J Respir Cell Mol Biol. May 152009

7. Keijzer R, Puri P. Congenital diaphragmatic hernia. Semin Pediatr Surg. 2010;19:180-185

8. Stoll C, Alembik Y, Dott B, Roth MP. Associated 
malformations in cases with congenital diaphragmatic hernia.Genet Couns. 2008;19:331-339

9. Numanoglu A, Steiner Z, Millar A, Cywes S. Delayed presentation of congenital diaphragmatic hernia. S Afr J Surg. 1997;35:74-76

10. Haugen SE, Linker D, Eik-Nes S, Kufaas T, Vik T, Eggen BM, Brubakk AM. Congenital diaphragmatic hernia: determination of the optimal time for operation by echocardiographic monitoring of the pulmonary arterial pressure. J Pediatr Surg. 1991;26:560-562

11. Nakayama DK, Harrison MR, Chinn DH, Callen PW, Filly RA, Golbus MS, De Lorimier AA. Prenatal diagnosis and natural history of the fetus with a congenital diaphragmatic hernia: initial clinical experience. J Pediatr Surg. 1985;20:118-124

12. Takahashi H, Hayashi S, Miura Y, Tsukamoto K, Kosaki R, Itoh Y, Sago H. Trisomy 9 mosaicism diagnosed in utero.Obstet Gynecol Int. 2010

13. Moya FR, Thomas VL, Romaguera J, Mysore MR, Maberry M, Bernard A, Freund M. Fetal lung maturation in congenital diaphragmatic hernia. Am J Obstet Gynecol.1995;173:1401-1405
14. Stege G, Fenton A, Jaffray B. Nihilism in the 1990s: the true mortality of congenital diaphragmatic hernia. Pediatrics.2003;112:532-535

15. Vijfhuize S, Schaible T, Kraemer U, Cohen-Overbeek TE, Tibboel D, Reiss I. Management of pulmonary hypertension in neonates with congenital diaphragmatic hernia. Eur J Pediatr Surg. Oct 2012;22(5):374-83.

16. Van Meurs K. Is surfactant therapy beneficial in the treatment of the term newborn infant with congenital diaphragmatic hernia? J Pediatr. 2004;145:312-316

17. Bartlett RH, Gazzaniga AB, Toomasian J, Coran AG, Roloff D, Rucker R. Extracorporeal membrane oxygenation (ECMO) in neonatal respiratory failure. 100 cases. Ann Surg.1986;204:236-245

18. Keijzer R, van de Ven C, Vlot J, Sloots C, Madern G, Tibboel D, Bax K. Thoracoscopic repair in congenital diaphragmatic hernia: patching is safe and reduces the recurrence rate. J Pediatr Surg. 2010;45:953-957.

19. Sweed Y, Puri P. Congenital diaphragmatic hernia: influence of associated malformations on survival. Arch Dis Child. 1993;69:68-70.

\section{How to cite this article?}

Wasey WA, Srivastava SK. Congenital Diaphragmatic Hernia: Atypical Early X-Ray Presentation. Int J Med Res Rev 2014;2(4):389-392. doi: 10.17511/ijmrr.2014.i04.23 